\title{
Encuesta sobre el lenguaje inclusivo
}

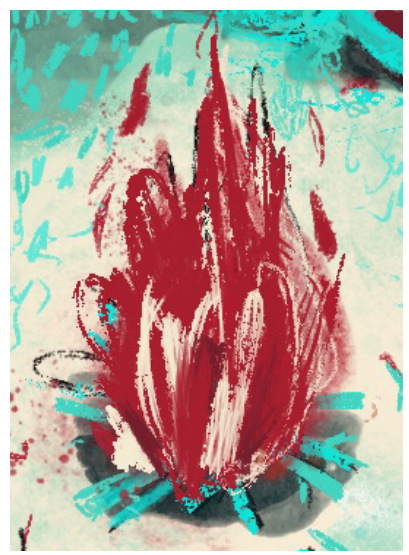

En este número de Signo y Seña presentamos las respuestas a una encuesta que, a propósito del lenguaje inclusivo, realizamos entre lingüistas de nuestro país. La idea de la consulta no fue la de añadir aprobaciones o reprobaciones sobre la cuestión, una polémica instalada hace unos pocos años en los medios de comunicación y redes sociales, pero con antecedentes de interés en diferentes culturas académicas, grupos sociales y poblaciones jóvenes. En el contexto de la polémica, la encuesta buscó obtener reflexiones alrededor de algunos ejes conceptuales que sirvan para ampliar el horizonte obvio que media entre la apología y el rechazo.

Los ejes elegidos, organizados a partir de preguntas que servirían de orientaciones para la reflexión, son los siguientes:

" Eje A: Lenguaje y realidad. ¿Cuál es el vínculo entre lenguaje y realidad? $\dot{¿ A l}$ modificarse el lenguaje se modifica la realidad? ¿Al modificarse la realidad se modifica el lenguaje? ¿El lenguaje crea la realidad?

" Eje B: Lenguaje y morfología. ¿Lenguaje inclusivo o una variante morfológica? ¿El castellano puede desarrollar una morfología nominal no binaria (por ejemplo, femenino, inclusivo y masculino)?

"Eje C: Lenguaje y regulación lingüística. ¿Qué tanto nos pertenece la propia lengua, la manera de expresarnos? ¿Puede regularse el uso de la lengua? ¿El inclusivo pone en riesgo la inteligibilidad del castellano?

El valor que encontramos en este formato de encuesta, cuestionable 0desde cierto punto de vista (el por qué se eligieron esos ejes de reflexión y no otros, o más sencillamente, el por qué se propusieron ejes), es que diferentes especialistas en ciencias del lenguaje ofrecen puntos de vista convergentes y divergentes sobre algunos tópicos vinculados con el llamado lenguaje inclusivo. De esta manera, desde el ámbito académico se brindan algunas reflexiones conceptuales más amplias que tal vez resulten apropiadas para enmarcar las respuestas que, con mayor y menor entusiasmo, se vienen ensayando en el debate público argentino.

A continuación, entonces, las respuestas de las personas que aceptaron participar de la encuesta, ordenadas alfabéticamente por sus apellidos 


\section{Alicia Eugenia Carrizo}

Profesora en la UBA. Doctora en Lingüística. Se dedica al análisis del discurso argumentativo, actualmente estudia la violencia verbal.

\section{Lenguaje y realidad}

El lenguaje crea la realidad mediante el uso de múltiples de recursos que nos provee la lengua y el universo semiótico que nos rodea. Pero la dinámica creativa del lenguaje no tiene consecuencias en términos concretos del mundo físico. La realidad y el lenguaje se interrelacionan permanentemente de manera dialéctica. Interpretamos el mundo de acuerdo con nuestra estructura cognitiva previamente desarrollada pero, al mismo tiempo, muchas veces, la realidad se nos impone de distintas maneras, a veces crueles e inentendibles -tanto que nos quedamos sin palabras para (re)presentarla. La dimensión de lo que podemos ver, decir y encuadrar en el lenguaje tiene siempre una lectura histórica específica que no debemos dejar de lado. Sostener que el lenguaje modifica la realidad o es modificada por él simplifica enormemente lo que sucede. Muchas veces, una palabra amable nos calma y reconforta, pero lograr una transformación significativa de lo que nos da dolor o angustia internamente, implica distintas dimensiones que van más allá de lo personal e involucra aspectos sociales, económicos, políticos e ideológicos, además de cognitivos. Por otro lado, la reflexión sobre el alcance y efectos de la relación del lenguaje con la realidad está presente no solo en los científicos, sino sobre todo en los hablantes. Basta enfocar el uso del lenguaje en contexto.

\section{Lenguaje y morfología}

El lenguaje inclusivo es el modo que en la actualidad se refiere al uso no sexista del lenguaje. Si bien la reflexión académica de la relación de hombres y mujeres en el uso del lenguaje tiene relativa tradición en la sociolingüística, actualmente ha dado lugar a posicionamientos enfrentados a favor y en contra que trascienden la academia y afecta la vida cotidiana de las personas. Los que defienden el lenguaje inclusivo se proponen cambiar ciertos recursos gramaticales de la lengua que, en el caso del español afectan la morfología, en especial, el uso del género masculino como genérico. Cambiar la gramática es cambiar la estructura de la lengua y por ende, el modo en que conceptualizamos a la mujer. Los que se oponen también sostienen esta misma idea, pero difieren en el origen y dinámica de esos cambios, que claramente excede la sustitución de una forma por otra. 
Si, en el futuro, se consolida una morfología nominal no binaria en el sistema del español, estaríamos ante un hecho sin precedentes, porque no solo significaría el triunfo de los movimientos sociales de ampliación de derechos sino porque tendríamos la posibilidad de estudiar el cambio de la lengua mediante herramientas teóricas y metodológicas innovadoras. En estos términos, sería un extraordinario desafío para lingüistas y científicos en su conjunto.

\section{Lenguaje y regulación lingüística}

En principio la lengua no nos pertenece como no nos pertenecen tampoco nuestros pensamientos ni nuestros sueños ni nuestra memoria. La relación no es de pertenencia, como algo que se compra y pasa a ser de uno individualmente como un derecho de propiedad. El vínculo es de convivencia, la lengua vive (y muere) internamente en nosotros.

Por otra parte, el uso no puede regularse porque ya está regulado de antes. Las convenciones nos preceden, siempre. Es decir, un cambio o modificación en la regulación de la lengua (entendida como normativa o conjunto de reglas convencionalizadas) da lugar a una lucha entre las posiciones a favor o en contra. Instalar una nueva regla implica la movilización de un grupo importante de usuarios en pos del mismo o similar objetivo. Es posible que, en la actualidad, la confluencia de los medios de comunicación, las redes sociales y las instituciones estatales encaminadas a ese fin, puedan generar una modificación de uso del lenguaje; pero el resultado de esta lucha se podrá visualizar en el futuro, en nuevas las generaciones que la reciban como dado.

No creo que el inclusivo ponga en riesgo la inteligibilidad del castellano, en tanto es un ejemplo (como cualquier otro) de la convencionalidad del lenguaje. 


\section{Juan Antonio Ennis}

Profesor en Letras por la UNLP. Doctor en Filología Románica por la Universidad de Halle-Wittenberg. Profesor adjunto de la cátedra de Filología Hispánica en la FaHCEUNLP. Investigador de CONICET con lugar de trabajo en el IdIHCS (UNLP-CONICET).

\section{Lenguaje y realidad}

Creo que en sí la pregunta puede resultar un poco engañosa. Quiero decir con esto que para poder ofrecer una respuesta clara y concluyente a la primera pregunta deberíamos saber también de manera clara y concluyente qué es el lenguaje y qué la realidad, y ese no parece ser siempre el caso. Aunque parezca paradójico, creo que la segunda pregunta es más sencilla de responder. Sin caer en los extremos de ciertas vertientes del llamado giro lingüístico, creo sí que la codificación lingüística incide sobre el designatum, y esto en varios niveles. No se trata solo de los límites que se imponen a la materia o a lo social a través de la designación, sino también de las posibilidades que ofrece la sintaxis. En muchas formas, también, creo que es en muchos casos evidente que la realidad se impone al lenguaje. Decir que el lenguaje crea la realidad me resulta al menos exagerado. Sin embargo, eso no quita que no puedan hacerse cosas, muchas cosas, con palabras.

\section{Lenguaje y morfología}

Creo que en este plano todo es posible. No es sencillo, no va a resolverse ni a imponerse de un momento a otro, pero creo que la morfología puede ser sensiblemente modificada en respuesta a la política. No conocemos aún todas las posibilidades del lenguaje como dispositivo fundamental de la construcción política de la comunidad, y probablemente el solo hecho de constituirse en espacio posible de esa controversia, de esa tensión, nos esté hablando de esas posibilidades aún no vislumbradas. Creo que si podemos concebir un modo de vivir el género que exceda el binarismo, podremos también necesitar una codificación lingüística para eso. $\mathrm{Y}$ a medida que se internalice, también puede gramaticalizarse.

\section{Lenguaje y regulación lingüística}

El uso de la lengua puede regularse del mismo modo que pueden regularse múltiples conductas, y con los mismos límites y alcances que ese tipo de regulaciones alcanza en otros aspectos. La posibilidad de regimentar una lengua, de someterla a un régimen de propiedad, es en mi opinión uno de 
los sedimentos del modo de organizarse la experiencia lingüística tal y como la conocemos, al menos en nuestra modernidad. El fantasma de la ininteligibilidad es un reflejo arcaico, empleado cada vez que un determinado orden glotopolítico se ve amenazado, interpelado o siquiera molestado. Hay infinidad de rasgos que pueden hacer más o menos ininteligible una variedad del español frente a otras variedades, y eso no despierta tanta inquietud como el inclusivo. El problema del inclusivo, en mi opinión, no es la lengua, sino lo que dice de su régimen. 


\section{Mabel Giammatteo}

Doctora en Letras, especializada en Lingüística por la Facultad de Filosofía y Letras de la UBA. Profesora titular de Gramática (FFyL, UBA). Coordinadora de la Diplomatura Superior en Ciencias del Lenguaje del ISP “Dr. Joaquín V. González”.

\section{Lenguaje y realidad}

El vínculo entre lenguaje y realidad no es directo ni sencillo. No se trata de una relación biunívoca en la que cada palabra se corresponda con algún correlato extralingüístico, como planteaban las teorías referencialistas. Asimismo, como es bien sabido, tampoco las lenguas designan las mismas entidades de la misma manera. Por ejemplo, aunque los "apéndices articulados" en que culminan las extremidades superiores e inferiores de nuestro cuerpo sean los mismos para todos los seres humanos, en inglés se refieren a ellos como finger si se encuentran en la mano, pero usan toe cuando se trata de los del pie; en español, en cambio, en ambos casos usamos dedo. Ejemplos de este tipo podrían multiplicarse, incluso en sentido contrario: mientras en español distinguimos entre pez (animal vivo) y pescado (animal muerto), en inglés usan fish en ambos casos. Pero, ¿qué pasa en una misma lengua cuando cambia la realidad? ¿Cada vez que surge algún elemento nuevo creamos una nueva palabra? No necesariamente, muchas veces extendemos "metafóricamente" alguna palabra ya existente, como cuando utilizamos virus para referirnos a un programa que afecta al funcionamiento de nuestras computadoras o cuando "navegamos" por Internet sin subirnos a ningún vehículo ni realizar ningún desplazamiento a través del mar. Y si la realidad preexistía, pero cambia, ¿el lenguaje se adapta y también cambia? Las primeras maestras normales que trajo Sarmiento al país desde los EEUU tenían por contrato que no podían casarse mientras desempeñaran su función. Ahora ya no sucede eso, pero los niños en las escuelas siguen llamando "señorita" a sus maestras, aunque estas ya no tienen la prohibición de contraer matrimonio. Todos estos ejemplos provienen del léxico, el área más dinámica de las lenguas. Los sistemas gramaticales, a los que pertenecen los subsistemas de género, por ser los que garantizan la inteligibilidad de las lenguas, son aún menos permeables al cambio, ya que muchos de los significados que transmiten se remontan a los orígenes de la lengua y son opacos para los hablantes actuales, que entonces tampoco están interesados en modificarlos. Excepto claro está, que esos contenidos transmitidos se vuelvan significativos por alguna circunstancia, como parece ser que está sucediendo con el género.

Ahora bien, ¿cómo se organizan en las lenguas los sistemas de género y qué aspecto o aspectos de la realidad manifiestan? Las lenguas organizan 
la partición en géneros (o clases, que es lo que significa en latín la palabra genus, de donde viene género) de diversas maneras; así, encontramos desde las que no tienen manifestación explícita de la categoría hasta las que reconocen dos, tres o más subclases. Las lenguas bantúes, por ejemplo, tienen hasta seis géneros. Sin embargo, no en todas las lenguas las distinciones de género tienen que ver con el sexo. Según explica Lyons (Introduction to theoretical linguistics; London: Cambridge University Press, 1968), las clasificaciones pueden estar vinculadas con otras particularidades de los objetos, como la forma, la textura, el color o incluso con alguna característica más específica como la comestibilidad; es decir, cualquier conjunto de propiedades naturales que pueda variar de una lengua a otra puede incidir en la clasificación. Pero también, en muchas lenguas que disponen del género como categoría de clasificación de los nombres, existe una base semántica "natural" para esta clasificación. En las lenguas que provienen del antiguo indoeuropeo (lengua de la que deriva la mayoría de las lenguas actuales de Europa y Asia meridional), se reconoce que existe una correlación del género con la distinción entre objetos inanimados, por un lado, y seres animados, entre los que luego se distinguió entre machos y hembras, por el otro, lo que dio origen a la distinción gramatical entre femenino, masculino y neutro.

En cuanto al género como manifestación de la discriminación social entre varones y mujeres, la realidad es que en la mayoría de las lenguas en las que se establecen distinciones de género, entre femenino y masculino, el que se toma como genérico, por lo general, es el masculino y esto, no podemos pensar que sea debido al azar o a la casualidad, sino que tiene que ver con que en muchas de esas sociedades han sido los varones los que han ejercido el dominio sobre las mujeres. Sin embargo, la situación de las lenguas en las que no existe distinción marcada de género, como el japonés o el turco, entre muchas otras, no ha sido garantía de que en esas sociedades no exista discriminación. La lingüista Ana Costa Pérez, en su tesis doctoral ("El género en las palabras y el género de las palabras: un acercamiento a la variable ideológica género a partir del fenómeno semántico de la heteronimia", Universidad Carlos III de Madrid, 2017 ), recoge el caso de lenguas como el guajiro, hablado en Colombia y Venezuela, en la que el femenino actúa como género no marcado, pero esto tampoco implica que en esa sociedad la situación de la mujer sea más favorable.

Por otra parte, un reciente informe de la Academia Argentina de Letras (2018) pone el acento en que más que debatir si un uso es o no discriminatorio, lo que importa es qué percepciones asocian con él los hablantes. Por tanto, lo que se puede plantear respecto de lo que está sucediendo en la actualidad con una categoría como la de género, es que muchos hablantes "sienten" que el masculino genérico no evidencia su verdadera situación $y$, en ese sentido, permitir el surgimiento de formas con las que se puedan sentir más representados, puede ser una buena manera de ejercer presión sobre la sociedad para que las cosas cambien. Por tanto, no basta con modificar el lenguaje para que la realidad de sometimiento y desventaja a la que todavía se enfrentan, en la sociedad actual, muchas mujeres y otras minorías sexuales cambie. Pero el desterrar del lenguaje formas que "naturalizan" 
esa discriminación, sin duda puede colaborar para ir creando consciencia respecto de esa realidad y que se generen acciones para modificarla.

\section{Lenguaje y morfología}

El español es una lengua "bifronte", es decir que considera solo dos variantes dentro de la categoría de género: masculino y femenino. La mayoría de los sustantivos tienen lo que se conoce como género inherente o inmotivado - casa (fem.), libro (masc.)-, lo que significa que es una propiedad de la raíz de la palabra, que solo se manifiesta en la concordancia con el artículo o con el adjetivo: la casa nueva / el árbol frondoso. Pero además del género inmotivado, una parte relativamente pequeña de los sustantivos, la que se refiere a seres animados, tiene "género motivado", en el que la distinción en masculino y femenino refleja la diferenciación entre seres sexuados, ya sea mediante el cambio en la desinencia: niña/niño, perro/perra, maestro/ maestra, ya sea mediante el cambio de palabra: hombre/mujer, vaca/toro.

En relación con esa oposición, tradicionalmente se ha considerado al masculino como el género no marcado o extensivo, que sirve para referirse a todos los individuos de una especie, sin distinción de sexos: el hombre contemporáneo, el león es el rey de la selva. Este empleo es el que se conoce como uso genérico del masculino y es habitual no solo en español sino también en otras lenguas que distinguen dos géneros.

Sin embargo, dado el avance de las mujeres en la sociedad, este valor de categoría no marcada del masculino está siendo cuestionado tanto en España como en varios países de Latinoamérica y, en todas partes, el reclamo ha originado numerosos y muchas veces encendidos debates en pro y en contra del uso genérico del masculino. Para contrarrestar el sesgo masculino en el lenguaje, en ciertos ámbitos primero se comenzó a adoptar lo que se conoce como doble mención: las niñas y los niños, a todos los vecinos y vecinas, la voluntad de los argentinos y las argentinas. La RAE, sin embargo, no recomienda este uso al que ha tildado de "artificioso e innecesario" desde el punto de vista lingüístico. En la comunicación cotidiana, la reiteración del nombre en ambos géneros no solo atenta contra la economía del lenguaje, sino que también se vuelve fastidiosa para los oyentes. Para evitar esta incomodidad, se han ensayado distintas propuestas. Dos de ellas, el reemplazo de la desinencia masculina por la letra $x$ o por la arroba -todxs nosotrxs o tod@snosotr@s-, tienen la dificultad de la inviabilidad de su pronunciación, lo que confina su uso al ámbito exclusivo de la escritura. Una tercera solución que se ha propuesto es usar la desinencia femenina como genérica, pero esta posibilidad tiene el inconveniente de inducir interpretaciones excluyentes de los varones.

La cuarta propuesta, que está ganando adeptos, especialmente entre los jóvenes, es el uso de la -e como desinencia genérica que permite abarcar a todas las minorías de género sin distinción. Este planteo desestima que, desde el punto de vista del sistema gramatical del español, la -e es marca de masculino tanto como la $-o$, tal como se puede ejemplificar con la serie 
de los demostrativos: este (masc.), esta (fem.), esto (neut.), o con oposiciones del tipo de elefante/elefanta, grandote/grandota. No obstante, para el uso inclusivo de la -e los hablantes (sin duda de modo no consciente) tienen en cuenta que la -e tiene usos con valor neutro, por ejemplo, en los adjetivos de una sola terminación, que sirven tanto para femenino como para masculino -hombre/mujer inteligente y tolerante-. La -e también actúa como vocal por defecto en español y es la que se agrega, por ejemplo, para enlazar la -es del plural cuando la palabra termina con consonante -árbol/ árbol-e-s- o delante de palabras provenientes del latín iniciadas por grupos consonánticos no aceptables en español -schola (lat.) > e-scuela (esp.)- . En síntesis, en el imaginario de los hablantes de español la -e es sentida como menos emblemática que la -o como marca de masculino, de modo que se permiten reinterpretarla como desinencia genérica que engloba, como se dijo anteriormente, a todos los colectivos de género posibles sin establecer diferencias entre ellos. Estos datos, sin embargo, no conducen necesariamente a la incorporación de un "tercer género" en la gramática, sino más bien, al menos por el momento, parece tratarse de formas disponibles para ser usadas en determinadas circunstancias de la vida social. Así como en español actual no tenemos género neutro, como sucedía en latín, pero persisten algunas formas de este género en el artículos -lo- y los demostrativos -esto, eso, aquello- y cuantificadores -alguno-; o así como sucedía en algunas lenguas como el griego, el latín o el egipcio, que tenían para la categoría de número, junto al singular y al plural, también un valor dual, que no se aplicaba a todos los nombres, sino que se reservaba para los casos de entidades que se dan en pares, como los ojos, las piernas o la yunta de bueyes; también las lenguas actuales podrían incluir formas de género inclusivo reservadas para aquellos casos en que fuera necesario hacer referencia común a individuos de distintos colectivos de género.

\section{Lenguaje y regulación lingüística}

La lengua es colectiva, porque nos permite comunicarnos con un grupo social del que formamos parte, que obviamente comprende variados subgrupos que se corresponden con diferentes lectos de referencia, y a la vez es la manifestación de nuestra máxima individualidad. En ambos sentidos, la lengua nos expresa. No obstante, también nos desborda y la regulación de su uso ha de ser siempre supraindividual, no porque dependa de autoridades externas, sino porque está sometida a la aceptación del colectivo social. Si la única vía de cualquier uso es la imposición, el intento estará destinado al fracaso, como cuando en la escuela del siglo pasado se quiso instalar el tuteo como reemplazo del voseo y los hablantes de todos los estratos socioculturales del dialecto porteño se mantuvieron fieles a la forma que sentían que los representaba genuinamente.

En cuanto a la inteligibilidad, he escuchado varios audios con el uso genérico de la -e y no he tenido ninguna dificultad en comprender lo que dicen. Algunos hablantes, sobre todo jóvenes, se muestran bastante habituados a expresarse de este modo y lo hacen sin dificultades. Como toda novedad en la lengua, si su uso se extiende y pasa de la esfera pública, donde parece 
estar más arraigado, al ámbito familiar, habrá que habituarse, y siempre habrá algunos colectivos que, por cuestiones generacionales o de interés, se involucren primero y con más facilidad en el cambio. Por lo pronto, este empleo ya se ha venido imponiendo en la lengua actual en algunas clases textuales, como el manual escolar, los textos periodísticos o administrativos, donde encontramos formas coordinadas que hacen mención explícita a ambos géneros.

Por otra parte, si bien esta propuesta ha recibido el rechazo de muchos lingüistas destacados que encuentran su uso artificioso, otros expertos rescatan que, frente a otros símbolos gráficos como la x o la @, la -e genérica presenta la ventaja de su pronunciabilidad. Asimismo, muchos de los que aceptan su empleo sostienen que, por el momento, estaría reservado a lo que podemos denominar uso público, sin embargo, dada la naturaleza dinámica y cambiante de la lengua, es todavía demasiado pronto para determinar tanto los alcances como la perdurabilidad de este cambio. No sabemos si se extinguirá, si quedará restringido al ámbito público, como un estilo particular, o si logrará extenderse a todas las funciones de la lengua, aún las familiares y coloquiales, y tampoco podemos aún definir si se trata de un rasgo exclusivamente cronolectal que dejará afuera a los mayores o si terminará imponiéndose a toda la comunidad. No obstante, debemos recordar que toda aceptación de una nueva forma no surge de la imposición, sino del hecho de que responde a una necesidad de los usuarios y por eso es aceptada y adoptada por la comunidad. 


\section{Andrea Menegotto}

Profesora titular de Gramática en la Facultad de Humanidades (UNMDP). Investigadora independiente, INHUS (Instituto de Humanidades y Ciencias Sociales, UNMDP), CONICET. Vicepresidenta de SAEL (Sociedad Argentina de Estudios Lingüísticos).

\section{Lenguaje y realidad}

Sin duda, la lengua tiene un efecto muy poderoso en nuestra manera de entender y construir el mundo, pero no la determina. Si así fuera, no surgirían visiones del mundo diferentes dentro de la misma comunidad lingüística.

$¿$ Es la cultura que nos rodea la que determina por completo la lengua que hablamos, o son las propiedades de nuestro cerebro las que la determinan? En el área de investigación a la que yo pertenezco asumimos que ninguna determina a la otra e intentamos discriminar cuánto aporta el cerebro y cuánto aporta la experiencia. El lenguaje crea realidades alternativas.

\section{Lenguaje y morfología}

Sí, sin duda. Hay que esperar que les chiques tengan hijes. Lo más difícil será que los presidentos, los gerentos y los agentos acepten el masculino morfológico. Veremos qué pasa.

\section{Lenguaje y regulación lingüística}

Ningún proceso de cambio pone en riesgo la inteligibilidad de una lengua en la sincronía, a menos que les hablantes decidan utilizar una lengua para que les otres no les entiendan. Todos los hablantos que coexistamos vamos a seguir entendiéndonos, y siempre les jóvenes crearán formas novedosas para diferenciarse de las generaciones anteriores. A lo sumo se podrán generar algunos malentendidos nuevos entre generaciones y grupos sociales diferentes (lo que ya existe sin necesidad del inclusivo).

Sí, las normas lingüísticas son parte del sistema y contribuyen fuertemente a construir la comunidad. Las reglas regulativas son inevitables, pero como tales pueden cambiar. 


\section{Salvio Martín Menéndez}

Profesor de Lingüística y Gramática Textual en la carrera de Letras (FFyL-UBA). Profesor de Lingüística I y II en la carrera de Letras (UNMDP). Investigador del CONICET.

\section{Lenguaje y realidad}

El vínculo entre lenguaje y realidad es constitutivo. El concepto de realidad está conformado, moldeado, por el lenguaje que usamos para hablar y escribir; para interactuar, en definitiva. Su propiedad básica y específica es la instrumentalidad. Hjelmslev lo afirmaba con precisión al decir que se solía pasar por alto que estaba en la naturaleza del lenguaje en ser un medio y no un fin. De ahí podría derivarse la concepción de Halliday, que es el primero que utiliza la expresión "lenguaje como recurso" (language as resource). Recurso, precisamos, para intercambiar y negociar significados. Si la especificidad del lenguaje pasa por ser el conjunto de los recursos necesarios que los miembros de una comunidad utilizamos para obtener determinados fines, es simple: los fines están creados por el propio lenguaje. Esto nos permite alejarnos del idealismo absolutista cartesiano, que consagra la pureza de la razón y una de sus derivaciones prácticas, la normatividad, y aproximarnos a un idealismo socio-cultural que nos acerca a la postura de Whorf: lo ideal en una comunidad depende, en última instancia, de la decisión de esa comunidad. Y esto no debe ser tomado simplemente como un relativismo cultural vacío y oportunista (esa sería la manera fácil y errada de considerarlo), sino como un relativismo cultural que depende de ese contrato social que una sociedad acepta para funcionar como tal y que es, tal vez, la mejor metáfora de lo que es la construcción de realidad. Contrato que tiene como condición de posibilidad para establecerse al lenguaje. Podríamos afirmar que el universo físico puede ser independiente de los seres humanos, pero, cuando damos cuenta de él (podemos decir: cuando le asignamos el nombre de "universo físico" y lo distinguimos, por ejemplo, del "universo cultural") estamos usando el lenguaje como un artefacto, como una construcción, como una obra de ficción. Que la realidad es una obra de ficción construida a partir del uso del lenguaje, es lo que los que trabajamos sobre él deberíamos aceptar. Parafraseo acá una frase de Ferdinand de Saussure en "De la doble esencia del lenguaje" cuando, en relación con las identidades lingüísticas afirma: "que se encuentra inmediatamente ante esa tarea absurda, es lo que el lingüista debe comprender de entrada" Aquí aparece la hipótesis que propone Hasan, con la que acuerdo y cuya argumentación trato de seguir, sobre esta relación: decir que el lenguaje es un conformador de la realidad es decir que el lenguaje es instrumental 
en sostener esta suspensión de descreimiento. El lenguaje es, entonces, el instrumento que lo permite en relación con la construcción de la realidad.

\section{Lenguaje y morfología}

Si entendemos, como he señalado en el Lenguaje y realidadnterior, que el lenguaje es un sistema de recursos que permiten su realización instrumental efectiva, podemos decir que la variante morfológica dentro del paradigma de género - $e$ es una posibilidad ya existente que se está, simplemente, tratando de refuncionalizar a partir de un uso concreto y efectivo, que se ha denominado popularmente lenguaje inclusivo. Este nombre provee una interpretación de un fenómeno que la lengua española habilita y que sus usuarios (algunos de ellos) deciden poner en funcionamiento. El lenguaje siempre es inclusivo, en sentido amplio, ya que construye la realidad en función de las necesidades que las comunidades que lo usan. Las únicas restricciones válidas son las que impiden que sus usuarios no puedan interactuar de manera efectiva. Potencialmente, podríamos afirmar, todos los paradigmas están abiertos. Que se pongan en funcionamiento estas posibilidades dependerá, como siempre, de quienes lo usan, de sus necesidades y de la productividad que ese uso tenga. No creo que haya problemas en ir más allá del binarismo, ya sea en la morfología u otras dimensiones en las que sea necesario. Cito una frase de Lavandera, en el último artículo que escribió parcialmente, llamado "Los nuevos axiomas de la lingüística" que, creo, puede leerse como una respuesta clara a si se puede ir más allá del binarismo: "La consecuencia más fácil de esta atadura creada por la permanencia de axiomas que pasan incuestionados es que se puede sostener con responsabilidad que en la lingüística contemporánea, pese a la aparente variedad de teorías y rupturas tajantes como la que parecería darse entre Formalismo y Funcionalismo, no logramos salir de un estructuralismo, es más, del estructuralismo estático".

\section{Lenguaje y regulación lingüística}

El alcance del significado del verbo "pertenecer" es, al menos para mí, problemático (será por recuerdos de publicidades que siguen vigentes y alientan la exclusión a partir de la pertenencia). Prefiero utilizar constituir; si entendemos que una lengua construye lo que nosotros aceptamos, más allá del grado de conciencia que tengamos al respecto, como "la" realidad, somos sus agentes conformadores porque la usamos y es ese uso el que le da su marca interaccional, social, cultural, histórica e ideológica. Lo que ahora se ha popularizado con el sintagma "lenguaje inclusivo" no es sino una muestra más de ese dinamismo. Y no creo que ningún dinamismo, que se expresa en variaciones en un momento determinado, que pueden o no transformarse en cambios de lo que la historia de la lengua da testimonio, puedan poner en riesgo la comprensión de una lengua; la razón es simple: si no se entiende, no se usa y si no se usa, se descarta. A partir de esto uno podría preguntarse ¿no será el "inclusivo" una moda? Sólo los hablantes y el tiempo tienen la respuesta. Los lingüistas podemos y debemos analizar 
el fenómeno. Podemos hacer una buena descripción, que lo explique y lo interprete. Podemos, con las debidas y explícitas aclaraciones, evaluarlo. Que pueda o no gustarme es algo que el lingüista dice como un juicio de valor como un hablante (porque, más allá de muchos reparos que se nos pueda hacer, lo somos) de la lengua; por eso debo siempre hacerlo explícito y precisarlo, para evitar confusiones. No debe hacer un uso indebido de su lugar profesional para intentar transformar un mero gusto en una supuesta norma. Nuestra tarea no pasa ni por la imposición ni por la prohibición. No somos policías de la lengua. No es nuestro papel. 


\section{Cristian Palacios}

Doctor en lingüística por la Universidad de Buenos Aires con especialización en los discursos cómicos y humorísticos, el teatro, la cultura para niños y el arte en general.

\section{Lenguaje y realidad}

Empezaría por diferenciar entre la realidad, que es un constructo sociocultural, semiótico y por supuesto también lingüístico, de lo real, que es aquello que nunca se deja asir del todo ni por el lenguaje ni por los diferentes modos semióticos que tenemos a nuestro alcance. Es verdad que el lenguaje construye la realidad y que a su vez se convierte en uno de los modos de accesos privilegiados a dicha realidad, pero ni es el único (hay otros modos de acceso y construcción de la realidad) ni es absolutamente determinante en este sentido. Entiendo que podemos tomar decisiones respecto del lenguaje que modifiquen la realidad lingüística, pero este proceso lejos de ser determinista es sumamente complejo, ya que dependerá de una multiplicidad de factores, entre los cuales se encontrará la resistencia propia de aquellos y aquellas que no deseen que la realidad lingüística se modifique.

\section{Lenguaje y morfología}

A priori no me parece que exista ninguna causa propiamente lingüística por la que el castellano no pueda desarrollar una morfología nominal no binaria; dependerá, claro está, de la resistencia de sus hablantes, de la resistencia social y de múltiples factores históricos y culturales. Creo que es más interesante la pregunta por el alcance político de una variante tal. Es decir, si la variante morfológica alcanza un grado de normalización que le permita ser incluida en la lengua al punto de que ya no sea percibida por los hablantes como una rareza, ¿seguirá conservando su potencial político? ¿cambiará eso las condiciones de existencia de las personas no binarias? Existen sociedades patriarcales que no flexionan en términos de masculino, femenino o neutro y no por ello dejan de ser menos patriarcales. Incluso podría pensarse que al revés, la normalización del lenguaje inclusivo silenciaría las tensiones sociales todavía existentes y al revés, el hecho de que lo inclusivo sea percibido como una rareza es lo que permite visibilizar dichas tensiones y darles un lugar en la lucha política.

\section{Lenguaje y regulación lingüística}


Respondo de atrás para delante. A la tercera pregunta absolutamente no. En principio porque pienso que la falta de inteligibilidad es la norma. Es parte del funcionamiento estructural del lenguaje el hecho de que sea poco inteligible o no-del-todo-inteligible. En este sentido, el uso de la lengua se puede regular y de hecho se regula, pero los patrones de regulación siempre fallan porque el lenguaje es cambiante, porque es propio de su naturaleza admitir la poesía, la metáfora, la reflexión filosófica, el humor, la política. Soy de la idea (un poco poética si se quiere) de que la lengua nos pertenece siempre y cuando nos dejemos habitar por ella. La lengua está en el mundo antes que nosotros y seguirá estando allí cuando nosotros no estemos en él. Por mi propia formación, debería argumentar que los sujetos no preexisten a la lengua en la que habitan, de modo que no nos expresamos con la lengua sino que es ella la que se expresa a través de nosotros; pero diré que existe un punto intermedio entre este uso que podemos hacer de la lengua, una decisión, y entre aquellas propiedades que esta posee y por las cuales solo podemos decidir en base a categorías ya definidas. 


\section{María Laura Pardo}

Investigadora principal del CONICET. Profesora de Análisis de los lenguajes de los medios masivos de comunicación social (FFyL-UBA). Presidenta de la Asociación Latinoamericana de Análisis del Discurso.

\section{Lenguaje y realidad}

En primer lugar, desde mi posición, no creo que exista una realidad real, a excepción de la realidad física (montañas, ríos, planetas, etcétera), que de cualquier manera también necesita de una construcción colectiva del mundo. Por lo que construimos colectivamente representaciones (conceptualizaciones) sobre el mundo que varían con el tiempo, según los grupos, creando y retroalimentando prácticas que conforman distintas culturas. El lenguaje como sistema biológico innato del hombre nos permite razonar y por ende clasificar las experiencias que tenemos de nuestro entorno y de ese modo construimos dichas representaciones a las que llamamos "realidad". Estas pueden ser modificadas a partir de nuevas experiencias (verbales -que se dan en el plano de la lengua- o no) que son clasificadas, categorizadas, valoradas por nuestro sistema lingüístico posibilitando un cambio en nuestras creencias sobre la "realidad". Es fundamental entender: (1) que sistema lingüístico no es la lengua, (2) que el sistema lingüístico trabaja de modo continuo, ya que es el que nos permite pensar, construir nuestra psiquis y nuestra identidad y, además, nos permite comunicarnos a partir de la lengua, (3) que la lengua es la puesta en uso de una de las funciones de este sistema, la comunicativa, (4) que la relación entre "realidad" y "lengua" es una relación que no es de uno a uno y (5) que la relación entre "realidad" y el sistema lingüístico tampoco lo es.

\section{Lenguaje y morfología}

Creo que el lenguaje inclusivo es una posición ideológica frente al uso de la lengua en relación a los géneros. Si pensamos que el lenguaje o sistema lingüístico crea realidades, podemos pensar que el uso del femenino, masculino y el neutro está condicionado por una visión determinada de la cultura. Toda visión sobre el mundo, está impregnada de subjetividad y de co-construcción social. Entonces, ¿por qué no intentar que se cambie la visión que sobre el género se tiene en la cultura? Qué mejor camino que tratar que el discurso (la lengua) construya una visión inclusiva del mundo que, a la vez, pueda cambiar la "realidad". El camino no será uno a uno, pero todos los cambios surgen a partir del uso. ¿Puede este uso forzarse? ¿Por qué no? O acaso cuando aprendemos a usar verbos irregulares como 
"caber", la gramática no nos fuerza a conjugarlo a contrapelo de lo que naturalmente sería "cabo" en vez de "quepo". La norma culta oculta (y vaya la cacofonía) una ideología, el uso del lenguaje inclusivo, para no ser autoritario, la hace explícita. Usemos la "e" como una forma no binaria y liberadora.

\section{Lenguaje y regulación lingüística}

La lengua es una cosa, la manera de expresarnos otra. La lengua es una construcción teórica, la manera de expresarnos es el uso concreto de eso que llamamos lengua, pero la lengua solo vive en el uso. Ese uso, como casi todos los bienes no tangibles de este mundo, nos pertenecen en tanto los poseemos, pero son obra de una construcción colectiva y, por lo tanto, social. $\mathrm{El}$ uso de la lengua lo regula la Real Academia, porque es un constructo teórico, al que cada tanto se le incorporan términos, pero el uso es libre. Puedo inventar palabras, puedo repetir parte de ellas como en el jeringozo, puedo hacer uso poético de ellas, el uso es eso: uso. Creo que el lenguaje inclusivo no pone en riesgo el buen uso del castellano, así como tampoco lo hace el uso de los adolescentes, ni de quienes dicen "de que" cuando no corresponde, ni la jerga atribulada de los abogados, ni el "si tendría" de los comunicadores, entre muchos otros usos, que aunque "incorrectos", "irreverentes", "osados" o "revolucionarios", narran los cambios que vivimos como sociedad. 


\section{Luis París}

Investigador del CONICET. Coordinador del Grupo de Lingüística y Neurobiología Experimental del Lenguaje (INCIHUSA-CONICET). Profesor titular de la UNCuyo. Ph.D. University of New York at Buffalo.

\section{Lenguaje y realidad}

Claramente sí se modifica la realidad. La realidad más radicalmente modificada es la subjetividad porque el lenguaje le permite al niño vincularse con el otro en el espacio del mundo del sentido. En ese mundo esa subjetividad puede, primero, absorber las innumerables narrativas de su entorno (principalmente materno) que van a mediar su relación con las cosas, los otros y los discursos de su entorno y, segundo, expresar sus deseos, miedos, necesidades y planes, es decir, ser un sujeto productor de sentido. Está implicado en lo dicho que las narrativas son las que despliegan y construyen el sentido de las cosas; el sujeto no se enfrenta a las cosas crudas sino a las cosas narradas, cosas con sentido, es decir, cosas incorporadas e integradas a la esfera de lo humano.

\section{Lenguaje y morfología}

Me parece que sí porque se trata de una especie de tercer género que ya existe en otras lenguas: el neutro. No digo que sea equivalente, digo que sistemas morfológicos con tres géneros funcionan. En este caso, además, la semántica de este tercer género morfológico es bastante clara: se trata de un uso genérico por defecto (para referirse a un grupo con distintos sexos o potencialmente de cualquier sexo) y para referirse a grupos o un individuo cuya identidad sexual de género (cultural) no es necesariamente binaria o que eligió una identidad de género diferente a la genital.

\section{Lenguaje y regulación lingüística}

La lengua es absolutamente nuestra -a nivel comunitario e individual- y no considero que deba regularse en absoluto en los términos en que se regula algo socialmente, es decir, por leyes coercitivas. La lengua es un espacio de libertad y tiene su regulación propia asociada a factores como la consistencia de la forma con el sistema simbólico en cuestión, la eficacia comunicativa, la valoración del oyente respecto del hablante, la estética misma de la forma, el contexto sociocultural, etcétera. La regulación por parte de una academia es una aberración, un contrasentido, un oxímoron. 
Peor aún es si se la intenta regular por el estado. Sin embargo, la escuela tiene que enseñar una lengua. ¿Cuál? Difícil pregunta, pero la idea básica es que debe enseñar la lengua que facilite la adquisición de conocimiento formal (matemáticas, lengua, historia, geografía, etcétera) y que fomente interacciones sociales valoradas como positivas. Al mismo tiempo, yo no vería mal que la escuela abordara la temática de los insultos y expusiera la temática del abuso verbal, qué efecto tiene en un niño el insulto, cómo lo daña, y qué hace el insulto con el insultador, en qué lo convierte. Yo me crié en una época en que poner sobrenombres era la norma (de hecho, los sobrenombres nos eran dados por adultos en el club, los entrenadores) y hoy al recordarlos no puedo creer lo brutalmente agresivos que eran y sin embargo los usábamos con normalidad. Hubiera sido fantástico que alguna maestra hubiese intentado hacernos ver el daño que hacíamos diciéndolo "monstruo" -por lo feo- a un tal Pérez, del que nunca supe cómo se llamaba en realidad, al punto de que si tengo que preguntar qué es de la vida de él a alguien tendría que usar ese espantoso apodo. 


\section{Alejandro Raiter}

Profesor, licenciado y doctor en Letras. Profesor consulto de la Facultad de Filosofía y Letras (UBA). Estuve a cargo de Sociolingüística, de Psicolingüística l y de Psicolingüística Il.

\section{Lenguaje y realidad}

Es una pregunta difícil, el tema se viene discutiendo desde hace mucho tiempo. Mi opinión es que sí hay vínculo y que este es estrecho. Dialecto y sociolecto -no lengua ni, desde luego, lenguaje- están íntimamente relacionados con la cultura, la historia, el sentido común de una comunidad. Si algún hablante cambiara de dialecto -por adición o sustracción-, cambiaría también su visión del mundo, sin duda.

La realidad social y el dialecto forman una unidad indivisible. No cambia uno sin que cambie la otra; tampoco cambia la realidad social sin que las huellas del cambio estén en el dialecto. Ninguna de las dos cambia por decreto, la realidad social puede cambiar abruptamente (por catástrofes, guerras).

Si entendemos crear como algo mágico, como la acción de Dios, la Pachamama o la Naturaleza, no: el lenguaje no crea la realidad.

\section{Lenguaje y morfología}

Mi opinión personal es que el llamado lenguaje inclusivo consiste en el uso de variantes fonológicas y ortográficas, al menos por ahora. Tal vez implique cambios en el sistema pronominal en el futuro.

Creo que un eventual dialecto inclusivo del español evitará marcar género cuando pueda.

\section{Lenguaje y regulación lingüística}

Totalmente; el dialecto hablado en la comunidad constituye el ser individual quien, en ese acto se apropia de ella para trascender y adueñarse de la relación.

La regulación es posible, al menos es posible intentarlo. Toda comunidad tiene una organización. Algunas -muchas- tienen autoridades, incluso autoridades lingüísticas, a veces por ser simplemente autoridad educativa 
o religiosa. Esta autoridad forma parte de la comunidad, de modo que si intenta un cambio es porque está autorizada para ello. Muchas veces, no obstante, encuentra resistencia activa y/o pasiva para ese intento. Pensemos en la RAE, en la autoridad -no recuerdo ahora su jerarquía- de la francofonía, en el hebreo moderno, en la BBC, etcétera.

Pensar que el inclusivo pondría en riesgo la inteligibilidad de algo así como el castellano equivale a pensar que la conquista de la Galia es culpable del reemplazo del latín por las lenguas romances. 


\section{Yamila Sevilla}

Doctora en lingüística por la Universidad de Buenos Aires. Es investigadora adjunta del CONICET y jefa de trabajos prácticos de la materia Neurolingüística de la Facultad de Filosofía y Letras (UBA). Se ocupa de investigar experimentalmente los procesos de comprensión y producción de lenguaje en adultos sin alteraciones del lenguaje y en personas con afasia.

\section{Lenguaje y realidad}

En las relaciones sociales, la dimensión simbólica es constitutiva tanto como la dimensión material, de modo que cualquier transformación en una de ellas, se trate de un cambio abrupto o de un desplazamiento paulatino, ha de tender a producir modificaciones sobre la otra. Eso no significa que el lenguaje se modifique en consecuencia. La tradición lingüística nos ha mostrado que las lenguas ofrecen a los hablantes todos los recursos necesarios para decir lo que necesitan decir; también, de hecho, que los mensajes que los hablantes desean transmitir pueden variar entre grupos y con el tiempo. Los fenómenos que impulsan el cambio lingüístico son, sin embargo, mucho más intrincados que la percepción de un grupo de hablantes sobre la naturaleza de sus intercambios o que la reflexión expresa sobre las formas de decir. Mucho se ha investigado sobre estas cuestiones, que exceden largamente el campo de mi especialidad, y cuyo escrutinio merece poner sobre la mesa variables que no habilitan vinculaciones causales directas.

Más próximo a mi área de estudio, la cuestión puede enfocarse a partir de la relación entre lenguaje y cognición. Aunque tiene una historia mucho más antigua, la reflexión sobre las relaciones entre lenguaje y pensamiento tienen su formulación más definida en la hipótesis Sapir-Whorf. Hasta el día de hoy, la investigación empírica más comprometida con la exploración sistemática de esta hipótesis ha producido un cuerpo de evidencia compatible con una versión débil, que sostendría que los hablantes tienden a prestar mayor atención a ciertas distinciones conceptuales cuando estas se hallan presentes en su lengua.

Contemporáneamente, el modo en el que se han estudiado los vínculos entre el lenguaje y la cognición sigue a la propuesta de Dan Slobin, a la que se conoce como "pensar para hablar". Tal como lo plantea Slobin ("From 'thought and language' to 'thinking for speaking'", en Rethinking linguistic relativity, Cambridge: Cambridge University Press, 1996), cuando uno adquiere una lengua, aprende también ciertas maneras de pensar sobre la realidad. Siguiendo un programa en esta línea, muchos experimentos translingüísticos han intentado comprobar la influencia de los sistemas de categorización de las lenguas sobre la conceptualización y sobre la percepción de sus hablantes. 
Si cierta correlación entre habilidades cognitivas diversas (vale para la orientación espacial o el razonamiento aritmético) y propiedades de las lenguas parece estar documentada hasta cierto punto, no obstante, demostrar la relación de causalidad requiere pruebas diferentes. Incluso, la dirección de las influencias también puede ser bastante difícil de probar. Y, en cualquier caso, los límites de las experiencias humanas de la percepción, la conceptualización y la codificación lingüística no van nunca más allá de lo que los sistemas humanos de percepción, categorización y codificación permiten y muestran un grado de variabilidad que, aunque puede estar definido por muy diversos factores, incluida la historia cultural, parece ser relativamente acotado.

Para citar un ejemplo vinculado a la cuestión del género, un conocido trabajo ha intentado demostrar que la asociación género-sexo tiene influencia incluso sobre nuestra forma de concebir las entidades no sexuadas, como los objetos. En el estudio, hablantes de distintas lenguas debían indicar atributos para una serie de objetos cuyos nombres diferían en el género en las distintas lenguas (palabras como "sol", "luna", que manifiestan diferente género gramatical en español y en alemán). Según el estudio, los hablantes de alemán eligen para "puente", femenino, atributos como "elegante" o hermoso", mientras que los hablantes de español prefieren atributos como "fuerte" o "largo", es decir que hacen asociaciones estereotípicamente femeninas o masculinas según su lengua (Boroditsky, Scmidt y Phillips, "Sex, syntax and semantics", en Language in mind: Advances in the study of language and thought, Massachusetts: MIT Press, 2003). En otro estudio, los hablantes debían poner en correspondencia imágenes de objetos cuyos nombres tenían distintos géneros con voces humanas, que podían ser femeninas o masculinas. Los autores encontraron una mayor tendencia a identificar las versiones animadas de los objetos cuyos nombres manifiestan género femenino con voces femeninas y a animar con voces masculinas los que poseen nombres con género masculino. Otros estudios no lograron reproducir los mismos efectos de manera sistemática (Sera et al., "When language affects cognition and when it does not: An analysis of grammatical gender and classification", Journal of Experimental Psychology General 131(3), 2002). Muchos de estos experimentos están poblados de dificultades metodológicas, sesgos de concepción y falta de explicitación de supuestos básicos; cada uno de ellos debería examinarse puntualmente, pero, en conjunto, poseen un valor muy relativo y conclusiones discutibles.

La idea de que la lengua guía nuestro razonamiento en función de las distinciones que nos exige hacer y la noción de que influye directamente sobre la manera en que interactuamos con la realidad no cuentan por ahora con evidencia empírica incontestable. Al menos eso parecen indicar los estudios que muestran que no hay correlación entre el grado de marcación de género morfológico en la lengua y equidad de género en las sociedades.

\section{Lenguaje y morfología}

El lenguaje inclusivo aparece de la mano de una demanda de visibilización de la situación de desigualdad estructural que viven las mujeres en la 
sociedad y de rechazo a la discriminación de ciertos grupos en relación con el género. En este sentido, puede leerse como una estrategia de intervención política, cuyo valor cabe evaluar mucho más por la potencia de sus efectos sociales, que por el éxito o el fracaso de su incorporación sistemática a la variedad lingüística en cuestión.

Por la misma razón, no parece que haya definiciones específicamente disciplinares demasiado relevantes para introducir a la discusión en esta instancia. Y, sobre todo, la trayectoria del fenómeno no es algo que pueda predecirse o valorarse. Dicho esto, hay muchas dimensiones en las que la lingüística tiene un campo fértil de investigación e incluso de intervención. Desde el punto de vista descriptivo, no existe hasta el momento una caracterización rigurosa del fenómeno gramatical, ni de la extensión de su uso, en términos tanto sociolingüísticos como dialectológicos. Tocará a la sociolingüística investigar, posiblemente a posteriori, la capacidad de los grupos de traccionar el cambio lingüístico y de comprender en qué medida las formas novedosas logran codificar significados sociales de acuerdo con las necesidades de interacción de los grupos. Por otra parte, la capacidad de imponer la implementación de políticas movilizadas desde el estado y las instituciones normativas pertinentes depende de factores que no hacen, evidentemente, al lenguaje per se. Pero si, como empieza a observarse, se dan acciones sistemáticas de política lingüística institucionales, destinadas a fijar norma y promover de manera consecuente la sanción de los usos no normativos, la mirada disciplinar podría volverse primordial.

En relación con mi área de investigación específica, el panorama es igualmente poco transitado. En primer lugar, todavía hacen falta estudios empíricos que muestren que los hablantes de nuestra variedad interpreten el genérico como masculino. Hay, de hecho, indicios de lo contrario. Evidencia de distintas fuentes experimentales, más bien, abona la hipótesis de que la forma -o (y sus equivalentes) es una forma por defecto que no tiene asociado un rasgo de género interpretable. Bajo esta óptica, la única representación con contenido semántico asociado sería la del femenino. Existen también algunos trabajos preliminares que indican que, en la comprensión de oraciones, los hablantes (todavía) tienen más dificultades para comprender cuando se utilizan las distintas formas del inclusivo comparado con las formas del genérico. Los estudios, aún muy preliminares, que indican que las personas tienden a imaginar referentes que incluyen participantes femeninos o grupos mixtos cuando se utiliza cualquiera de las formas del inclusivo que cuando se utiliza el genérico en -o podrían interpretarse en el mismo sentido: estas formas no son neutras, sino que tienen marcación de género ( + femenino o + no binario, quizás) por contraste con las del genérico en - $o$, que no posee género semántico asociado.

Este dato en ningún caso pretende minimizar el hecho de que un conjunto cada vez más importante de personas manifiesta la necesidad de hacer visible lo que históricamente viene siendo material y simbólicamente negado u omitido y señala el uso del genérico como representativo de esa invisibilización. Empíricamente, puede resultar interesante explorar las tensiones expresivas, aquello que podemos querer decir y para lo cual no parecemos 
tener a mano una forma que resulte ahora eficiente, como los géneros no binarios, y el modo en que los hablantes estarían dispuestos a sortear esas limitaciones utilizando recursos propios de la variedad, adaptando formas o creando soluciones nuevas. Un ejemplo: una mujer resulta el caso destacable dentro de un conjunto que es mixto; el uso normativo del genérico indicaría: "X, el mejor exponente del conjunto Y". Todo parece indicar que esa fórmula no funciona bien: "La estrella brasileña Marta Vieira da Silva, se convirtió en la máxima goleadora en la historia de los Mundiales, ya sean masculinos o femeninos. Además consiguió otra proeza inédita: ningún hombre o mujer había anotado en cinco Mundiales distintos" ( $\mathrm{La}$ voz, 18 de junio de 2019). La psicolingüística es buena para preguntarse, dada una emisión, ¿qué entendemos?, ¿cómo llegamos a construir esa representación?, ¿qué análisis compiten en su construcción?, ¿cómo intervienen nuestras expectativas (los procesos top-down) en ese cómputo? Quizá pueda darnos algunas ideas sobre lo que está pasando en este momento con las formas que nos resultan, de un modo u otro, incómodas.

\section{Lenguaje y regulación lingüística}

El uso de la lengua puede, desde luego, regularse. Existen muchos medios para ello, la escuela por ejemplo. Ninguna institución reguladora, sin embargo, determina ni contiene por completo la acción de los múltiples factores que intervienen en el uso efectivo de la lengua y su modificación en el curso del tiempo. Tiendo a pensar que ningún experto en cambio lingüístico, un asunto muy lejano a mi especialidad, hablaría en términos de riesgo. Incluso en el caso de las llamadas lenguas minorizadas o amenazadas, suele pensarse que la amenaza es sobre la comunidad y su cultura, mucho más que sobre la lengua en sí. Con todo, las fuerzas homogeneizadoras parecen ser, según quienes entienden del tema, más poderosas que las de diversificación entre las variedades de nuestra lengua. 


\section{Graciana Vázquez Villanueva}

Profesora Adjunta de Lingüística Interdisciplinaria y Sociología del Lenguaje. Investigadora del Instituto de Lingüística (FFyL). Doctora en Letras y posdoctorado en Ciencias Sociales y Humanidades (UBA).

\section{Lenguaje y realidad}

Estos interrogantes cuentan con variadas posiciones, a veces en contraste absoluto, otras con algunos puntos de acuerdo. En cuanto al lenguaje inclusivo, ya la elección del adjetivo, implica un determinado sentido. Dado que inclusivo no es lo mismo que incluyente, igualitario o no sexista. Por esa razón, escojo para mi propuesta el significado "no sexista" para relacionarlo con los restantes ejes de la encuesta.

Antes de reflexionar sobre el lenguaje inclusivo pensamos en la llamada "cuarta ola" del feminismo, iniciada a principios de los 90 y caracterizada por un despertar, una toma de conciencia mayoritaria y una lucha global contra la opresión de las mujeres (Guzmán y Bonan, "Feminismo y modernidad", Debate Feminista 35, 2007.). Consideramos que la realidad y el lenguaje en uso se moldean mutuamente, independientemente de los estudios que, en el caso del lenguaje inclusivo, se han realizado de manera tardía con respecto a las movilizaciones feministas. Para comprender esta modelización desde la sociología del lenguaje se tienen en cuenta los principales rasgos sociopolíticos que investigaciones sobre la ideología de género han relevado sobre este tema. En primer lugar, el feminismo actual, por tercera vez en su historia, se ha convertido en un movimiento de masas. Antes lo había sido con el sufragismo y más tarde, con el feminismo radical, ${ }^{1}$ pero en este caso, presenta una novedad: el feminismo es global. No hay país en el que no haya -de una manera u otra- feminismo desde Estambul a Argentina, EEUU o Nueva Delhi.

Su segunda característica es la interseccionalidad que ha hecho efectiva su movilización global. Siguiendo a Rosa Cobo, no habría sido posible trasladar el mensaje y convencer si el feminismo no hubiese asumido la diversidad de las mujeres y, al mismo tiempo, no hubiese vuelto a poner sus energías en las políticas económicas, sociales, educativas de distribución. Es decir, por un lado, el feminismo se ha "ensanchado" y se hizo global internamente, para luego hacerse global externamente. Esto significa que "ya no hay que elegir un bando", entre el movimiento feminista y el antirracista, por

1 El feminismo radical o tercera ola es una corriente feminista que surge en Estados Unidos a finales de los años 196o. Centrada fundamentalmente en el logro de la legislación igualitaria sostiene que la raíz de la desigualdad social en todas las sociedades ha sido el patriarcado, el sistema de opresión del varón sobre la mujer. 
ejemplo. La interseccionalidad -según Kira Cochrane- es el principio rector de las feministas actuales y, además, ha traído un efecto no esperado: la exigencia de autoevaluación de privilegios. ${ }^{2}$

Un tercer rasgo está definido por la tecnología. Internet permitió al feminismo construir un movimiento on line fuerte y reactivo. Las redes sociales provocan un nuevo tipo de acción, ejercida por multitudes anónimas organizadas de forma rápida y precisa, con objetivos claros y comunes, con una estrategia que puede discutirse y planificarse. Las redes crean conexiones virtuales permanentes que van concientizando a grupos cada vez más jóvenes y relacionados en todo el mundo. Grupos que nacen en el mundo virtual y luego sienten la necesidad de organizarse en sus respectivos ámbitos, acercándose al movimiento feminista organizado, o creando sus propios grupos feministas -mujeres campesinas, universitarias, mineras-. El cuarto rasgo es que se ha consolidado la alianza con el ecologismo y, a su vez, el desarrollo del ecofeminismo, por ejemplo "las mujeres del agua" en Perú.

La cuarta ola también es intergeneracional. No hay relevo generacional porque nadie se ha ido. Se está produciendo un diálogo intergeneracional en el que feministas de larga trayectoria trabajan junto a mujeres jóvenes compartiendo liderazgos, propuestas y discursos. Esta novedad suma a millones de mujeres jóvenes; algunas, incluso, organizadas desde la educación secundaria. Finalmente, este feminismo se caracteriza por estar impugnando el modelo no solo en los regímenes autoritarios sino también en democracias con déficit de legitimidad y enfoca fuertemente sus críticas en el neoliberalismo.

\section{Lenguaje y morfología}

Solo el sintagma Guía de lenguaje inclusivo en español arroja en Google 2.890.000 resultados. Tras esto emerge lo "políticamente correcto": manuales del "deber" decir no sexista. Frente a esto el interrogante sería ¿el lenguaje es el que incluye? o ¿la sociedad es incluyente o discriminatoria? En otra Guía, que pretende contribuir a la eliminación de estereotipos de género en uno de los países con más desigualdad en América Latina, se afirma:

El sexismo lingüístico es el uso discriminatorio del lenguaje en razón del sexo. Como afirma la lingüista Eulalia Lledó, "el lenguaje no es sexista en sí mismo, sí lo es su utilización. Si se utiliza correctamente también puede contribuir a la visibilización de la mujer" (Guía de lenguaje inclusivo de género, Consejo Nacional de Cultura y Artes, Gobierno de Chile, 2016).

La defensa del lenguaje como "no sexista y "si su utilización" ubica ya una construcción ideológica en obviedad. Sin embargo, ¿qué ocurre con ciertos términos, por ejemplo gobernanta/gobernante? Femenino/masculino con - $e$ indudablemente marcan una diferencia de significado entre un oficio

2 En 1990 Judith Butler plantea que el género se construye socialmente en su libro El género en disputa. A partir de allí sostiene la necesidad de repensar el sexo, el lenguaje, la identidad y el sujeto. 
con menor prestigio frente a otro que es el ejercicio de gobierno. Desde lo morfológico lo inclusivo no tiene cabida. Allí es donde debemos pensar no en lo morfológico binario, sino en el género no binario que tiene que ver con los sujetos (o la construcción de subjetividades) que no se identifican con lo femenino/masculino sino con su elección individual por determinados géneros para sentir que afirman su identidad. En este sentido, nociones como bigénero, trigénero, agénero, género fluido o tercer género, nos reclaman salir de la morfología para comprender estos fenómenos socioculturales donde el lenguaje tal vez llega a sus límites. Una prueba son los trabajos de Tjasa Kancler, profesor de la Universidad de Barcelona y activista transgénero que utiliza el español no inclusivo en sus trabajos académicos. Lo mismo ocurre con el filósofo transgénero Paul Preciado en sus últimos estudios sobre el COVID-19 (Paul Preciado, "Aprendiendo del virus", El País, 28 de marzo de 2020). En consecuencia encontramos que la morfología o el uso del lenguaje inclusivo no pueden dar respuesta a esta pluralidad de elecciones de identidad o a la escritura, académica o no, de las problemáticas corpogenéricas o de salud. Sí, en cambio, constatamos que, en el mundo de la hispanofonía, el lenguaje inclusivo ha servido como un elemento más de mercado lingüístico. Para ello vale la pena detenerse en Guías para el uso no sexista del lenguaje publicado on line por el Ministerio de Sanidad, Servicios Sociales e Igualdad del Gobierno de España en 2015 (http://www.inmujer.gob.es/servRecursos/formacion/GuiasLengNoSexista/ docs/Guiaslenguajenosexista_.pdf). Se enuncia en su introducción que es una recopilación de documentos que "tratan de dar respuesta" a las necesidades previstas en el "Plan para la igualdad entre mujeres y hombres". Universidades, ayuntamientos, diputaciones y Gobiernos Autónomos de España brindaron su producción que presentamos en el siguiente cuadro. Como dijimos antes, "guías del correcto decir" donde no sólo no se analizan las cuestiones identitarias de género, sino que se privilegian los ámbitos económicos, administrativos y los recursos web ubicando en una posición subalterna a la educación, la salud, la ciencia.

\begin{tabular}{lc}
\hline Ámbitos & Documentos \\
\hline Academia & 17 \\
\hline Administración & 32 \\
\hline Comunicación y publicidad & 18 \\
\hline Cultura y Deporte & 9 \\
\hline Discapacidad & 2 \\
\hline Educación & 8 \\
\hline Empleo, empresa y relaciones laborales & 13 \\
\hline Jurídico & 2 \\
\hline Salud & 5 \\
\hline Sensibilización general y recursos web & 14 \\
\hline Sociedad Civil & 5 \\
\hline Ciencia, Tecnología y Medio Ambiente & 4 \\
\hline
\end{tabular}




\section{Lenguaje y regulación lingüística}

Considero que antes de responder sobre "qué tanto nos pertenece la lengua", prefiero expresarlo en términos de Foucault: "la temática del ser del lenguaje" debe ser reemplazada por "la temática de lo que hacemos con el lenguaje". En la medida en que nos detenemos en este último aspecto, empezamos a pensar en que las prácticas discursivas son formadoras de la subjetividad. Principio sostenido por la cuarta ola del feminismo: construcción de género, de identidades, de lenguaje. Desde esta perspectiva, obviamente sí puede regularse el uso de la lengua, por corrección o por diferencia, si consideramos los estudios de Bourdieu a Derrida. En cuanto al lenguaje inclusivo, como antes mencionamos, la regulación es bien explícita.

June Jordan, activista, poeta negra, cuyo lenguaje es el inglés negro, y cuyo nombre se encuentra en el Muro Nacional del Honor LGBTQ afirmó que las políticas de la identidad "pueden ser suficientes para empezar algo, pero no son suficientes para conseguirlo". Para Jordan, lo fundamental es lograr la equidad y la solidaridad. Ya que categorías como mujer, negro, negra, indígena, lesbiana, gay, trans nos sirven solo para la articulación política, no pueden ser fines en sí mismos, solo sirven para enfrentar al enemigo y no para encontrarnos entre nosotros. Es esta tensión permanente entre "lo profundamente personal y lo profundamente político", lo que confiere justamente luminosidad a la lengua. El lenguaje inclusivo se regula. Y si se regula es para evitar el ostracismo de identidades.

En la Argentina, un ejemplo es la Guía para el uso del lenguaje inclusivo en cuanto al género publicada en febrero de 2020 por la Dirección Ejecutiva del Instituto Nacional de Servicios Sociales para Jubilados y Pensionados (http:// www.algec.org/wp-content/uploads/2020/02/GUIA-LENGUAJE-INCLUSIVO. pdf). En este documento se plantea entre sus prioridades la igualdad real de género, el respeto a la identidad de género y a la orientación sexual, así como también el enfoque de los derechos humanos en las políticas destinadas tanto al personal que trabaja en el Instituto como a todas las personas afiliadas. Al leer el documento se observa claramente que el lenguaje inclusivo no pone en riesgo el castellano, por más que en su introducción se mencione que el purismo, aparentemente, ha desatado tensiones con respecto al uso del lenguaje inclusivo.

Lo políticamente correcto establece "el uso generalizado", al que se rechaza, en oposición "al uso inclusivo o no sexista" y lo hace al tomar como fundamento no al lenguaje sino a la situación comunicativa: "1. Evitar expresiones discriminatorias; 2 . Visibilizar el género cuando lo exija la situación comunicativa; 3 . No visibilizar el género cuando no lo exija la situación comunicativa”. Ahora bien, si las violencias machistas permean la realidad y se inscriben en el lenguaje, ¿qué ocurre con el esclavismo sexual de niños y hombres? Solo con buscar "violación de hombres y niños" en Google, muchas veces perpetrados por mujeres, no solo se ve el silencio sino la emergencia de estereotipos como "los varones son fuertes", "los 
varones siempre quieren sexo" como establece Sara Stemple (UCLA) ${ }^{3}$ en un libro en coautoría, Sexual violence against men in global politics (London: Routledge, 2018).

Concluimos con lo establecido por Florencia Graciani con respeto a que el concepto de lenguaje no sexista toma como realidad el desarrollo natural del lenguaje a través de la historia, de manera tal que cuando la historia marca diversas tendencias el lenguaje tiende a una mayor inclusividad que cuando estos cambios se generan en la sociedad. La lengua puede ser de todas y de todos, no es un sistema rígido, cerrado a cualquier mutación, sino al contrario, el cambio está previsto en las mismas estructuras. El lenguaje es un sistema dinámico, un medio flexible en continua transformación, potencialmente abierto a escribir en él infinitos significados, y por ellos, también la expresión de la experiencia humana femenina, o LGBTQ. Estas palabras introducen uno de los libros más claros sobre este tema: La educación lingüística; Trayectorias y mediaciones femeninas, de Luisa Spencer, donde se muestra la importancia de entender que un lenguaje debe ser inclusivo, incluyente, no sexista, adaptativo para sobrevivir, seguir vigente y conformar una sociedad humana más igualitaria. Los soportes y dispositivos ya lo hablan: series yankees, videojuegos, films, las instituciones de Estado redactan guías.

3 Lara Stemple es la Decana Asistente de Estudios de Posgrado y Programas para Estudiantes Internacionales en la Facultad de Derecho de la UCLA, donde supervisa el LL.M. de la facultad de derecho. (maestría) y SID (doctorado) programas de grado y dirige el Proyecto de Derecho de Salud y Derechos Humanos. Stemple enseña y escribe en las áreas de derechos humanos, salud global, género, sexualidad y encarcelamiento. 


\section{María Alejandra Vitale}

Doctora en Lingüística (UBA). Posdoctorado en Estudios Lingüísticos (UFMG, Brasil). Directora proyectos UBACyT. Investigadora del Instituto de Lingüística (FFyL-UBA). Área de investigación: análisis del discurso político y de servicios de inteligencia.

\section{Lenguaje y realidad}

Adhiero a la posición de N. Fairclough respecto de que existe una relación dialéctica entre lenguaje y realidad (social), la realidad (social) incide en el lenguaje y viceversa, al modificarse una se modifica el otro y viceversa. Desde mi punto de vista, esta posición supera el idealismo que subyace a afirmar que el lenguaje crea la realidad (social).

\section{Lenguaje y morfología}

Considero que hablar de variante o de lenguaje inclusivo depende de una posición glotopolítica, no creo que ningún lingüista asuma al usar el término lenguaje inclusivo que se trata de todo un sistema lingüístico nuevo o diferente. En relación con la - $e$, en una mesa redonda organizada por ABRALIN y SAEL se refirieron justamente a una "morfología inclusiva", ligada al estilo, a la situación comunicativa. En este sentido, en relación con la pregunta "El castellano puede desarrollar...", podría afirmarse que esa morfología nominal no binaria ya se desarrolló, pero el interrogante sería si puede convertirse en estándar. Por mi parte, puedo pensar el tema en términos glotopolíticos. Por eso considero que el castellano o español (una u otra denominación no es inocente) puede desarrollar una morfología nominal no binaria que se integre al estándar si las luchas simbólicas en torno a una norma de género llegan a resquebrajar la norma hegemónica y a sustituirla por otra. Se trataría de un proceso glotopolítico muy complejo con muchos actores involucrados.

\section{Lenguaje y regulación lingüística}

Es un hecho que el uso de la lengua se regula, por ejemplo, mediante la legislación lingüística. De modo que la respuesta es sí, se puede. Esto es objeto de estudio de la Sociología del Lenguaje. Por mi parte estudié cómo luego del golpe de Estado de 1943 el gobierno militar prohibió el uso del lunfardo en la radio, eso también es regular el uso de la lengua, en este caso mediante la censura. 
No considero que el inclusivo ponga en riesgo la inteligibilidad del castellano/español, entiendo que se trata de un argumento en contra del inclusivo basado en representaciones sociolingüísticas e ideológicas subyacentes que sería interesante rastrear.

La propia lengua, entendida como la manera de expresarnos tal como se desprende de la pregunta nos pertenece en el sentido de que nos da pertenencia, nos da identidad, pienso que hay consenso en eso. En cuanto a si es de nuestra propiedad, usamos la lengua y podemos expresar en ella posiciones glotopolíticas, como hablar de "cartel" en vez de "flyer", es decir que se trata de un bien social sobre el que tenemos derechos. Pero esos derechos están limitados por todas las convenciones y normas que nos vemos obligados a respetar para poder tomar la palabra, seguir siendo parte de nuestro grupo o aspirar a pertenecer a otro y lograr nuestros objetivos. 


\section{Julia Zullo}

Doctora en Letras (UBA). Profesora adjunta de Sociolingüística y Análisis de los Lenguajes de los Medios. Directora del proyecto UBACyT sobre transformaciones en el discurso político (Instituto de Lingüística).

\section{Lenguaje y realidad}

Uhh, las respuestas a estas preguntas dan para más de dos carillas, pero voy a ser breve: desde la perspectiva que nosotrxs encaramos como equipo, somos seguidorxs de Voloshinov, en el sentido de que un signo -cualquiera que sea- es a la vez reflejo y refracción de su contexto específico. Esto significa, volviendo a la pregunta, que en parte sí y en parte no: el uso del lenguaje es constitutivo de la realidad hasta cierto punto. Hay un lugar en donde la realidad excede al signo y viceversa, un lugar en donde el signo excede a la realidad, la modifica, la redefine. En este diferencial está la complejidad de la respuesta que además nos lleva a una cuestión semiótica más profunda que tiene que ver con el problema del significado, el sentido y la significación y pone en escena la posibilidad de ver el uso del lenguaje como un espacio de -potencial- conflicto y de disputa por esos espacios cuasisimbólicos.

En realidad, buena parte de los signos que usamos cotidianamente parecen no tener (o mejor dicho, no exhibir) ese diferencial, y vamos todxs contentxs por la vida pensando que las referencias son compartidas/lógicas/naturales. En algún momento, no cualquier momento y acá está lo interesante del debate, esa diferencia se hace manifiesta y muchxs hablantes reconocen que "la lengua no alcanza" para reflejar lo que está pasando o, peor aún, que la lengua "hace trampa". Quizás esto es lo más interesante de lo que está pasando actualmente en las discusiones sobre el "inclusivo", sobre todo en los debates en los que no solo participan lingüistas. Hay como una especie de sorpresa en este descubrimiento que, en realidad, para muchxs de nosotrxs es un fenómeno constitutivo del funcionamiento de las lenguas en sociedad.

Respecto de la segunda parte de la pregunta, y siendo consistente con esa posición teórica, pienso que es esta reflexión sobre la lengua la que podría permitir un cambio social. Nunca es una relación directa. De hecho, el Análisis Crítico del Discurso propone una dialéctica constante para explicar el cambio social y el cambio discursivo, pero los trabajos empíricos actuales que parten del análisis de textos nunca llegan a adoptar "el gran angular" que permitiría ver el cambio social. Sí se han hecho estudios históricos al respecto para demostrar esta dialéctica. Pero estamos hablando de un 
fenómeno muy reciente. Es preciso mucho tiempo para poder establecer si hubo o no alguna transformación social. Además, como todo cambio social está siempre sobredeterminado, se vuelve muy complicado -y bastante absurdo- tratar de establecer una relación uno a uno entre uso del lenguaje y sociedad, sin caer en debates estériles.

La otra cuestión interesante es preguntarnos hasta qué punto podemos establecer límites claros entre el uso del lenguaje y la sociedad. Desde los enfoques discursivos y lingüísticos (tanto franceses como ligados al funcionalismo de Halliday) sostienen que no hay forma de imaginar una formación social sin lenguaje, de la misma manera que no podemos imaginar un lenguaje sin su puesta en práctica. De ahí que muchxs lingüistas y analistas del discurso sostienen -y en esto coincido, más allá de la teoría en la que se inscriben- que estudiar el uso del lenguaje nos permite no solo explorar sus características, sus procesos de cambio (en suma, el sistema en funcionamiento) sino también, nos brinda una vía de acceso privilegiada al estudio de ese grupo, colectivo, sociedad que lo emplea. De manera que, volviendo a esta cuestión del lenguaje inclusivo, no solo no hay ni habrá una relación directa entre su utilización y las condiciones de vida de la diversidad de géneros en nuestra sociedad, sino más bien nos brinda la posibilidad, como estudiosos del lenguaje en uso, de estudiar las tensiones sociales, la necesidad de visibilización, el proceso de cambio que estamos viviendo como grupo humano. En este sentido, creo que hay que ampliar la mirada de las tensiones concretas, cotidianas que el lenguaje inclusivo suscita y empezar a ver estos usos como eventos comunicativos en los cuales se está dando un cambio de roles, de tareas, de derechos y responsabilidades que nos hablan de un proceso de cambio social mucho más profundo, complejo y mucho más a largo plazo.

\section{Lenguaje y morfología}

Creo que sí. No me dedico a la gramática, pero considero que en el proceso de cambio lingüístico las lenguas han sufrido cambios estructurales muy profundos a largo plazo. No sé si estaré viva para verlo, eso sí. Si los sociolingüistas tienen razón -y parecen haberlo demostrado-, una vez estabilizadas las formas nuevas -no estamos ni siquiera en esta etapa-, el sistema completo debería acomodarse/ajustarse a este cambio.

Si la primera parte de la pregunta se refiere a una disyunción, pienso que no. Lxs lingüistas sabemos que se trata de un fenómeno de variación morfológica eso que lxs hablantes están denominando "lenguaje inclusivo". Por ahora, es solo morfológica. Veremos más adelante si el cambio, como mencioné más arriba, llega a otros niveles del sistema.

Pienso que lo más interesante de este fenómeno de variación (por ahora no me atrevería a llamarle cambio lingüístico) es que no es un fenómeno típicamente sociolingüístico, en el sentido en que no se da la alternancia de formas nuevas inconscientemente. Esta variación, por el contrario, fue impulsada, visibilizada y puesta en circulación (y en tela de juicio por 
muchxs especialistas de las más diversas áreas y disciplinas) por un sector ajeno a las instituciones de la lengua. Creo que eso es lo que más rechazo genera tanto en los académicos como en otros sectores de la sociedad con cierto "capital simbólico" -como diría Bourdieu- que ven la intromisión en el uso de la lengua como una intrusión ilegítima: ¿quiénes son esxs para venir a decirme cómo se dice...? Esto es lo que hace de todo este proceso un fenómeno especialmente interesante y creo que único: una intervención política (y no normativa) sobre el uso que no emana de autoridades políticas de la lengua.

\section{Lenguaje y regulación lingüística}

Sí, la lengua materna nos pertenece totalmente si el pronombre "nos" es realmente plural e inclusivo (y perdón por la homonimia). Gracias a que nos apropiamos de ella colectivamente somos quien somos. Es nuestro carné de identidad. También, por supuesto somos creativos desde el punto de vista individual, claro está. Pero lo somos con limitaciones y esas limitaciones no solo tienen que ver con los parámetros de nuestra gramática sino también con las pautas de uso, de adecuación, de roles que nos brindan ciertos márgenes de variación.

Sostengo el principio sociolingüístico de que la variación es la cuna del cambio lingüístico, de modo que no me parece que esté en riesgo la inteligibilidad del castellano. Solo ocurre que en esta oportunidad se está visibilizando un proceso de cambio que en otras oportunidades no vemos (y mucho menos, polemizamos sobre él). En este sentido, creo que como lingüistas somos privilegiadxs por ser parte (más activa o más reactivamente) de este proceso. Tal vez solo se trate de un fenómeno profundo de variación que ha puesto en evidencia otros fenómenos sociales que están mucho más allá que el uso de cierta morfología. Tal vez, solo quede en las etapas preliminares del cambio lingüístico porque la particularidad que tiene este proceso -como dije más arriba- es que la variación nunca fue "desde abajo" del nivel de la consciencia -como dice Labov-, nunca se asoció a los usos cultos y prestigiosos del español o al menos, se distanció tempranamente de las instituciones que legitiman determinados usos.

Sin embargo, resulta interesante la tensión que se ha dado en tanto muchas instituciones académicas y educativas en general van poco a poco incorporando algunas de las variantes que muestra este patrón de variación, como posibles alternativas de expresión en todos sus géneros (orales y escritos). Y es interesante porque lo hacen como "opción", sin que la normativa pese sobre las espaldas de los y las hablantes/escribientes. 